\title{
Implementation of a Hybrid ANN-Based Filter for the Reduction of Harmonic Currents
}

\author{
José Abel Obando, Victoria Serrano* \\ Electrical Engineering Department, Universidad Tecnologica de Panama, Lassonde, West 6th Avenue, David, Chiriqui, \\ Panama
}

Corresponding Author Email: victoria.serrano@utp.ac.pa

https://doi.org/10.18280/ejee.230311

Received: 16 January 2021

Accepted: 29 April 2021

\section{Keywords:}

hybrid filter, odd harmonic, subharmonic, interharmonic neural network, harmonic distortion, damping, cycloconverter

\begin{abstract}
Harmonic distortions caused by non-linear loads (NLLs) affect the behavior of electrical systems, creating harmonics in the fundamental signal. As a result, this deteriorates the power quality. Therefore, this work proposes the implementation of a hybrid filter based on an artificial neural network (ANN) control system, focused on subharmonic, interharmonic and odd harmonic distortions generated by a three-pulse cycloconverter. In addition, a passive double tuned filter was implemented to damp even and odd harmonics. As a result, the simulation performed in MATLAB/SIMULINK showed that the responses produced by the ANN are approximate to the distortions present in the electrical system. Consequently, the levels of total voltage distortions (THDV) and total current distortions (THDI) are reduced. Therefore, the ANN control system improves the quality in the electrical network because the current and voltage harmonics comply with the electrical standards.
\end{abstract}

\section{INTRODUCTION}

Harmonics present in the electrical systems cause the heating of conductors, resonance in the elements of electrical systems which affects the operation of sensitive loads, causing deterioration in quality energy as it is shown in ref. [1]. Therefore, studies have been conducted on the design of filters based on injection current control to compensate for harmonics [2]. Furthermore, in literature [3], the detection of odd harmonics is presented for the training of neural networks. Also, in ref. [4] the design of an active filter with a two hidden layer control system is presented for the compensation of odd harmonics. Furthermore, in ref. [5], an active filter is presented with a control system based on ANNs optimized with particle swarm optimization. In the same way, Rajeshwari and Bagwari [6] presented a single-phase hybrid filter for compensation and damping of even and odd harmonics. In addition, in ref. [7] controllers based on neural networks were used to control the active and passive harmonics. Other studies have shown the deterioration of electronic elements $[8,9]$ that may vary the magnitudes and phases of voltages in loads, which generate lower frequencies than the fundamental frequency (known as subharmonics) [10]. Another possible effect may be the presence of not multiple frequencies of the fundamental frequency known as interharmonics [11]. However, although some of these studies proposed the compensation for different groups of harmonics, there has not been an evaluation of a single filter that compensate for all of them.

The purpose of our study is to design and implement a hybrid filter based on an ANN control system to compensate for odd harmonics, subharmonics and interharmonics. In addition, neural networks have been trained with harmonic signals caused by non-linear loads such as uncontrolled sixpulse rectifiers, controlled three-pulse rectifiers, and three- and six-pulse cycloconverters in MATLAB/SIMULINK. The Levenberg-Marquardt algorithm was also used to train the network.

For training purposes, the signals have been analyzed in the frequency domain, allowing the network to be trained in terms of magnitude and phase. Therefore, the input data are voltages with harmonics established in ref. [12], and the output data are electrical currents. A reference signal corresponding to the harmonics was generated, applying the pulse width modulation (PWM) technique for the triggers of the thyristors of the current source inverter (CSI). Subsequently, current harmonics are compensated, and voltage harmonics are lowered. In addition, in our study passive filters have been applied to attenuate the effect for the second and fourth order harmonics to complement a wider range of harmonics that might be generated in an electrical system.

This article is structured as follows: Section II describes the voltages in the electrical network, the electrical power of the motor and the frequency at which it operates. In addition, the frequencies corresponding to each neural network are selected according to the number of samples with harmonics. In Section III, the parameters implemented in the neural network are presented, such as the backpropagation algorithm that allow generalization of the training. This prevents overfitting the network. In addition, a regression analysis on post-training neural network of the three phases is shown. In Section IV, the results corresponding to the reduction of harmonic distortions are presented, by compensating the harmonic currents through the hybrid filter. Finally, Section V describes the conclusion obtained from the study. 


\section{NEURAL NETWORK HARMONIC DISTORTIONS}

TRAINING

WITH

The electrical grid was comprised of a $13 \mathrm{KV}$ in generation with a 100 MVA capacity, a $115 \mathrm{KV}$ in transmission and distribution and a $208 \mathrm{~V}$ in consumption. Moreover, the distance in transmission is $80 \mathrm{~km}$ where an ACSR Hawk-type conductor was implemented. Consequently, harmonic distortions were generated by three-pulse cycloconverters which generate subharmonics, interharmonics, and even and odd harmonics. Besides, a 33-level SCI was implemented due to the ability to reduce harmonic distortions at the output, in such a way that current harmonics were compensated without adding harmonics by the inverter [13, 14]. In addition, the double tuned filter was applied according to the technique in ref. [15], for damping the second and fourth harmonics of the current fundamental signal. This technique relates the impedances of the single tuned filters to obtain the capacitance and inductances in the double tuned filter. The schematic of the filter is displayed in Figure 1.

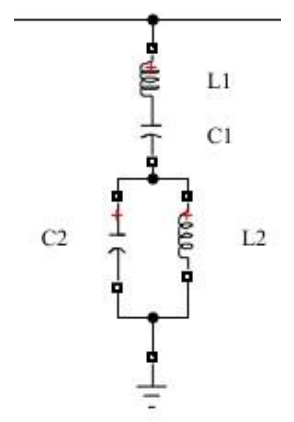

Figure 1. Passive double tuned filter

\subsection{Three pulse cycloconverter}

The frequency variation on the load was generated by the cosine wave crossing method that shifts the input voltages by 90 degrees; as a result, the voltage waveform was cosine [16]. Therefore, in the cycloconverters, the phase voltage, or the line voltage of the electrical grid was compared to the required level on the load for single-phase and two-phase motors. These comparisons in voltages generated pulses in the gate of thyristors in the cycloconverter, allowing current conduction towards the motor. On the other hand, the speed control technique was implemented through the voltage-frequency ratio in which the voltage must decrease linearly with the drop in frequency [17]. Consequently, frequencies in loads varied in a range between 15 and $105 \mathrm{~Hz}$. It is also important to mention that the loads were represented by single-phase and two-phase motors whose electrical powers vary from 0.5 to $200 \mathrm{HP}$.

\subsection{Harmonic frequencies}

Voltage signals were sampled according to the parameters established in ref. [18], at a resolution frequency of $2 \mathrm{~Hz}$. This provided the following number of distorted frequencies: 30 subharmonic frequencies, 359 interharmonic frequencies and 7 odd frequencies. However, harmonic frequencies of each neural network were based on the number of distortion samples generated by three-pulse cycloconverters. Therefore, frequencies were selected based on the number of distorted samples which represented thirty percent of the total samples.
Additionally, the magnitude of odd harmonics should not be greater than three percent of distortion in each frequency according to IEEE Standard 519 -1992 [19]. This was the same rule applied for subharmonic, interharmonic frequencies.

In Figure 2, the flow diagram depicts the process to obtain the harmonic frequencies. The programming steps of the diagram are detailed: first, the data is normalized to improve the capacity of relation in the training of ANN. The next step is the selection of data with values other than the minimum normalization range. Finally, the total percentage and the percentage of each harmonic is calculated, and the recurring harmonics are selected. As a result, the harmonic frequencies for the subharmonic networks are: 10, 14, 16, 20, 30, 40, 44, 46, 50, $58 \mathrm{~Hz}$. For interharmonic networks, the process delivered the following frequencies: 74, 76, 80, 90, 100, 104, $106,140,150,160,170$, and $210 \mathrm{~Hz}$. Finally, the odd networks were comprised of the following frequencies: 180, 300, 420, and $540 \mathrm{~Hz}$.

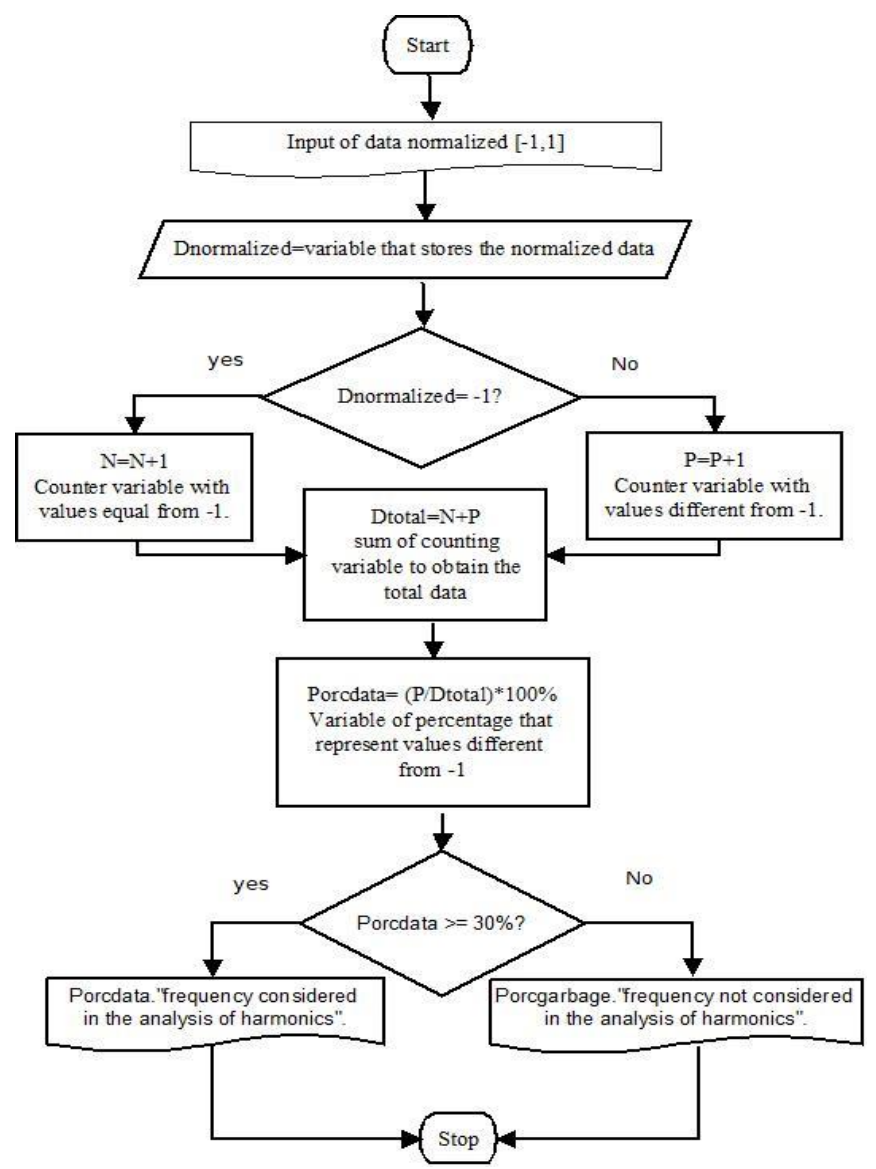

Figure 2. Harmonic frequency selections in ANN

\section{NEURAL NETWORKS}

For training purposes, the number of neurons in the hidden layer and the training algorithm that allows the generalization of data were selected in order to avoid overtraining.

\subsection{Backpropagation algorithm}

The Levenberg-Marquardt method is a backpropagation algorithm that combines the Gauss-Newton algorithm and the gradient descent algorithm during the training process, as detailed in ref. [20]. Therefore, when the performance of the error function increases, the gradient descent algorithm is used. 
On the contrary, when the performance of the error function is reduced, the Gauss-Newton algorithm is implemented.

The backpropagation algorithm applies the early stop technique and divides the data into three parts: training, the weights and biases are updated, and the neural network is trained. Besides, in validation, the error is supervised during the training process. Lastly, in test, the accuracy of the neural network is obtained. Therefore, the data was divided to have seventy percent for training, fifteen percent for validation, and fifteen percent for test. Additionally, when the training error increased, the network started to overfit up to the maximum number allocated for training. In this case, the number was 1,000 interactions; however, when the validation error increased up to six times, the training stopped.

\subsection{Neurons in the network}

The neural network was comprised of a hidden layer and the hyperbolic and sigmoid tangent functions for activation. Therefore, the data was normalized in the range of -1 to 1 . Additionally, to determine the number of neurons in the hidden layer, the Hecht-Nielsen theorem [21] was implemented. This theorem proposes the following concept: the number of neurons in the hidden layer is equal to $2 n+1$, where $n$ is the number of input nodes. However, in certain neural networks the number of neurons in the hidden layer that is required is greater or less than the established number by the theorem. Therefore, the number of neurons was increased or decreased until an appropriate correlation coefficient was obtained. It is also important to highlight that the subharmonic and interharmonic networks were trained with 1,410 samples and the odd harmonics with 360 samples.

In general, the network might be trained using magnitude or phase information data. In Figure 3, the interharmonic network was trained using magnitude values with 15 neurons in the hidden layer, 12 input nodes which represents the voltage harmonics, and 12 output nodes, which provides information about current harmonics.

On the other hand, Figure 4 shows the regression analysis in the subharmonic network in phase A, which establishes a linear relationship between voltage and current in terms of the harmonic generated by the cycloconverters. In addition, the networks were trained according to the harmonics that are generated in each phase. Moreover, in Table 1, a summary of the correlation coefficients of the subharmonic, odd and interharmonic network is presented. Also, the correlation coefficients in the test were greater than 0.90 . Therefore, since these coefficients were high, the network performed a generalization of the results to prevent data memorization. Likewise, similar results were obtained in the correlation coefficients for phase $\mathrm{B}$ and phase $\mathrm{C}$.

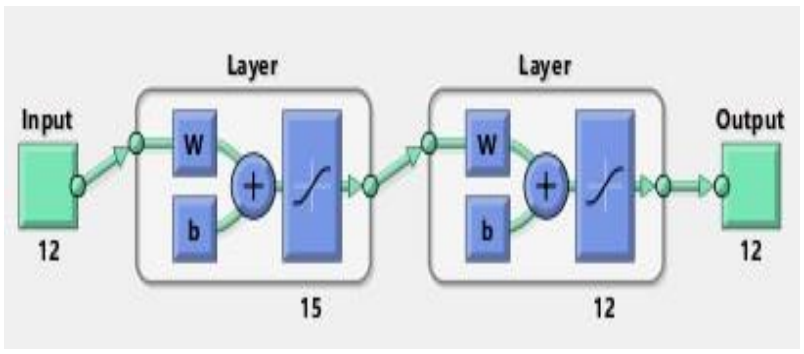

Figure 3. Interharmonic neural networks
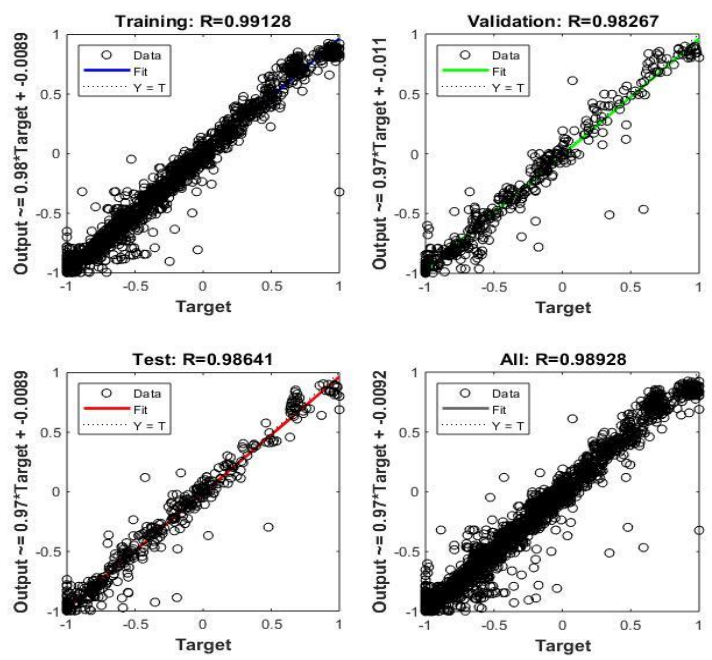

Figure 4. Regression analysis of ANN corresponding to the subharmonic network of magnitude in phase A

Table 1. Correlation coefficient of the ANN in phase A

\begin{tabular}{ccccc}
\hline Networks & Training & Validation & Test & All \\
\hline Magnitude & & & & \\
Subharmonic & 0.99 & 0.98 & 0.98 & 0.99 \\
Odd & 0.92 & 0.90 & 0.91 & 0.91 \\
Interharmonic & 0.99 & 0.98 & 0.98 & 0.99 \\
$\quad$ Phase & & & & \\
Subharmonic & 0.98 & 0.96 & 0.96 & 0.97 \\
$\quad$ Odd & 0.94 & 0.93 & 0.94 & 0.94 \\
Interharmonic & 0.98 & 0.98 & 0.97 & 0.98 \\
\hline
\end{tabular}

\section{RESULTS}

The proposed method applied in harmonic compensation was based on an ANN control system, which were trained with NNLs. The ANN input data was harmonic voltages and the output data was harmonic currents. Consequently, in the training process, neural networks determined a linear ratio between voltage and current harmonic distortions. According to the training, the ANN generated harmonic currents similar to those present in the electrical system. Therefore, these currents were introduced into the electrical grid to reduce the THDV and THDI. Besides, to demonstrate the capacity of the ANN as a control system for harmonic compensation, simulations were performed in the MATLAB / SIMULINK environment.

\subsection{Harmonic distortions in the electrical grid generated by the three-pulse cycloconverter}

Figure 5 shows a $13.8 \mathrm{KV}, 100 \mathrm{MVA}$ generator, and a 13.8 $\mathrm{KV} / 115 \mathrm{KV}, 40 \mathrm{MVA}$ step-up transformer in transmission. In addition, a $115 \mathrm{KV} / 13.8 \mathrm{KV}, 40 \mathrm{MVA}$ step-down transformer is observed in consumption. Also, a $13.8 \mathrm{KV} / 208 \mathrm{~V}, 100 \mathrm{KVA}$ transformer is shown in the electrical grid for the AC motor. Also, the operating characteristic of the motor is $208 \mathrm{~V}, 186$ W. However, the voltage level and the frequency of the motor was modified by the three-pulse cycloconverter to $138 \mathrm{~V}$ at a frequency of $40 \mathrm{~Hz}$. Consequently, the cycloconverter acted as a current source, generating subharmonics, interharmonics, even and odd harmonics. 


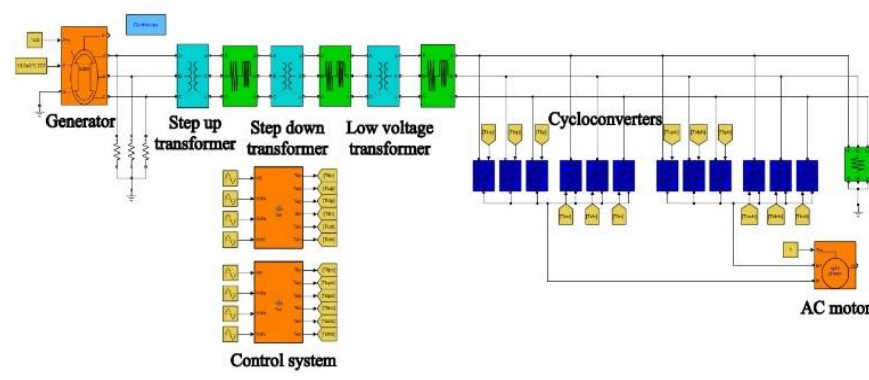

Figure 5. Three-pulse cycloconverter connected to a $208 \mathrm{~V}$ two-phase moto

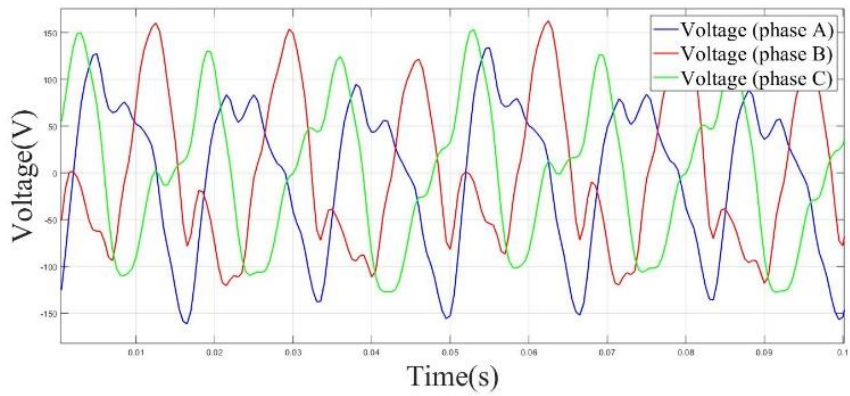

Figure 6. Voltage signal in the electrical grid

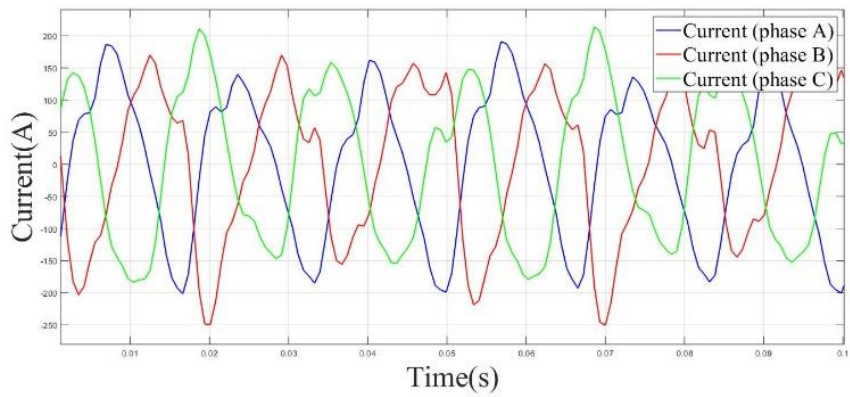

Figure 7. Current signal in the electrical grid

In Figures 6 and 7, voltage and current are shown when the three-pulse cycloconverter was operating. Consequently, the THDV in phase A, B, and C was $41.7 \%, 46.7 \%$, and $40.3 \%$, respectively. On the other hand, the THDI in phase A, B, and $\mathrm{C}$ was $28 \%, 37.4 \%$, and $38.15 \%$, respectively. Consequently, the analyzed signal showed a difference in the total distortion when all the phases were compared. Therfore, the distortions of voltage and current had a different magnitude when specific frequencies were analyzed. This is due to the distortions that were produced by cycloconverter when obtaining the frequency and voltage of the motor running. Therefore, the cycloconverters acted as harmonic sources changing the behavior of low voltage towards the electrical system.

Figures 8, 9 and 10 show the distortions in current for phases A, B, and C, respectively. This is given in the frequency domain that modified the shape of voltage and current of the electrical system. Some of the specifications of these distortions can be indicated as follows: in phase A at $80 \mathrm{~Hz}$, the harmonic current present was 9.8 amps with a phase angle of -96 degrees. Also, at the same frequency, the harmonic current was 25.7 amps at an angle of -90 degrees in phase B and 16 amps at an angle of -86 degrees in phase $C$. Furthermore, in the figure it can be seen that at the frequency of $100 \mathrm{~Hz}$, the harmonic current was $11.5 \mathrm{amps}$ with a phase angle of 49 degrees in phase A. It is also important to mention that in phase $\mathrm{B}$ the harmonic current was not taken into consideration because its effect on the electric current is approximately zero. In phase $\mathrm{C}$ the harmonic current was 10.8 amps with a phase angle of -125 degrees. Another variation in the behavior is shown in phase B for a different frequency. In this phase, a considerable harmonic current of $7.1 \mathrm{amps}$ at a phase angle of 18 degrees at $420 \mathrm{~Hz}$ was exhibited. Therefore, the variation of the harmonic distortion in the signals of the electrical system was caused by the performance of the motor when it operated with distorted signals.

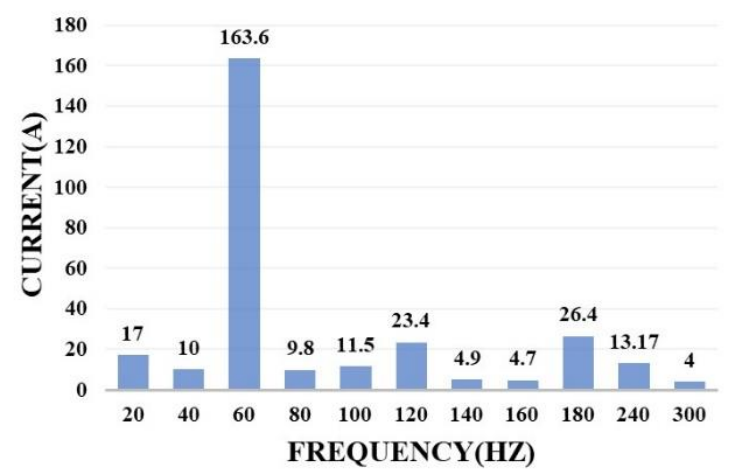

Figure 8. Current distortion in the frequency domain of phase A

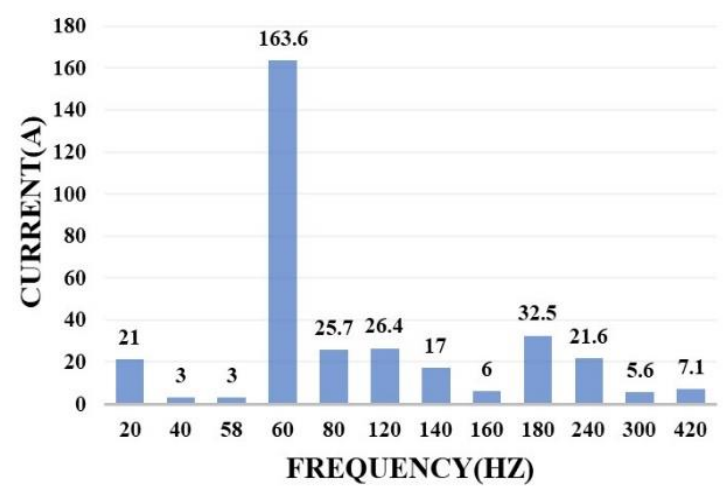

Figure 9. Current distortion in the frequency domain of phase B

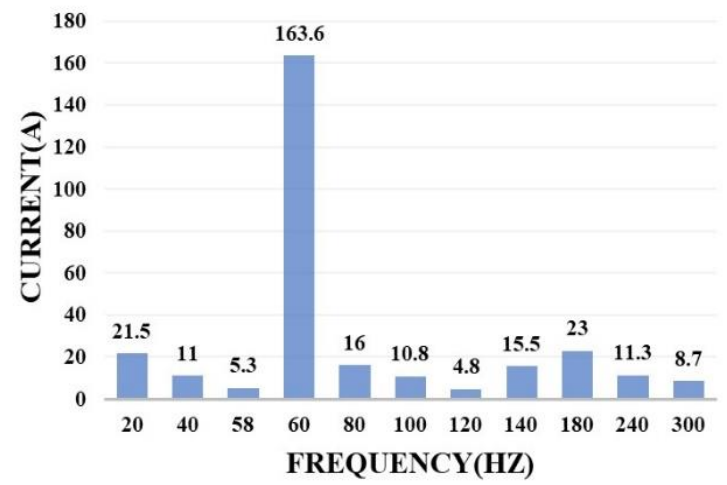

Figure 10. Current distortion in the frequency domain of phase C

On the other hand, even harmonics were not considered in the training of the neural network because they are not generated regularly by the cycloconverters. This causes the neural network to not relate adequately the voltage and current data due to non-recurrence of data. It is also important to 
highlight that even harmonics were dampened by the passive part of hybrid filter.

\subsection{Comparison of harmonics generated by the cycloconverter and ANN}

In Figures 11, 12 and 13 it is shown the harmonic current signals that affected the electrical system by distorting the fundamental signal voltage and current in the electrical grid. In addition, it is observed that the signal generated by ANN approximated the distortions that were produced by the effect of the cycloconverter. Consequently, the subharmonic, interharmonic and odd harmonic currents decreased according to the output data that was produced in the ANN.

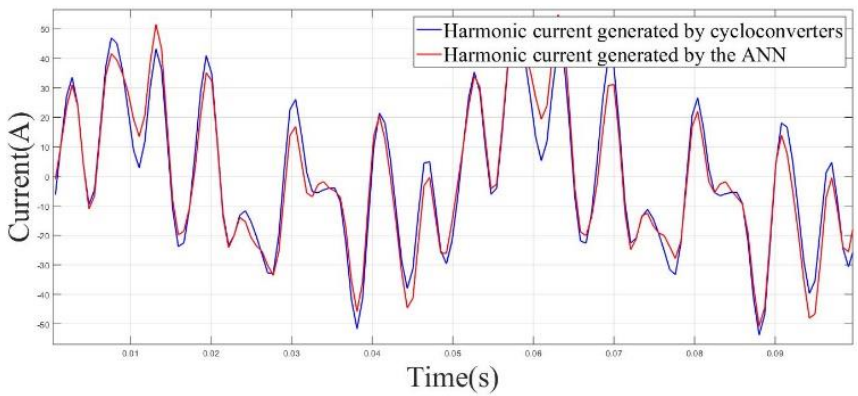

Figure 11. Harmonic current signal in the electrical grid and generated by the ANN in phase A

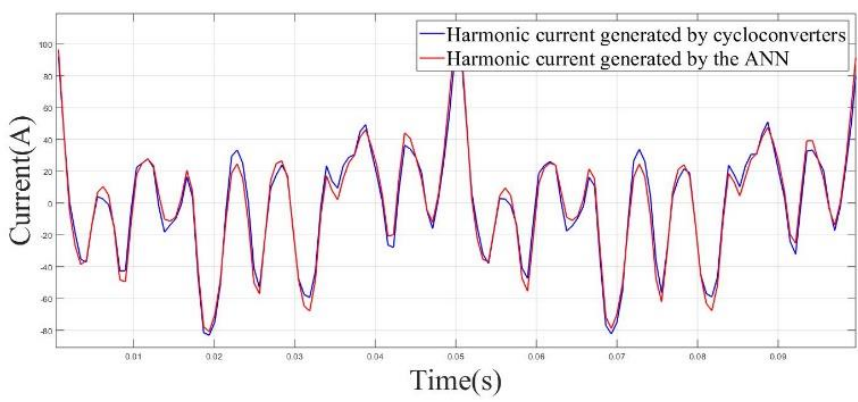

Figure 12. Harmonic current signal in the electrical grid and generated by the ANN in phase B

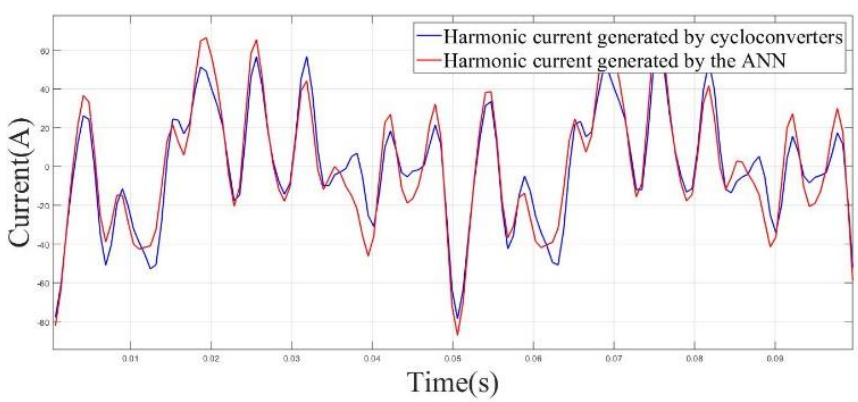

Figure 13. Harmonic current signal in the electrical grid and generated by the ANN in phase $\mathrm{C}$

Some comparisons between the harmonic currents in the electrical grid and the results from the ANN may be mentioned: in phase $\mathrm{A}$, at a frequency of $20 \mathrm{~Hz}$ the harmonic in the electrical system was 17 amps at a phase angle of 10 degrees; however, the ANN produced a response of 19 amps at a phase angle of 10 degrees. Likewise, the harmonics in phase B in the electrical system was 21 amps at an angle of 123 degrees, but the harmonic generated by the ANN was 23 amps at an angle of 118 degrees. Ultimately, in phase $\mathrm{C}$ the harmonic was 21.5 amps at a phase angle of -104 degrees and in ANN it was 21.5 amps at a phase angle of -91 degrees. Although there was a small difference between the results obtained from the electrical system and the ANN, the results of the ANN allowed to generate a harmonic compensation in such a way that the harmonic currents decreased. Consequently, the odd, interharmonic and subharmonic distortions in the power grid current were improved.

\subsection{Reduction of harmonics after training the ANN}

ANN's generated output signals, which were currents with odd harmonic, subharmonic and interharmonic that were added to encompass a total current. This was transmitted at 33level SCI by the PWM method to produce a current compensation in the power grid. These were the steps implemented to reduce harmonics in voltage and current.

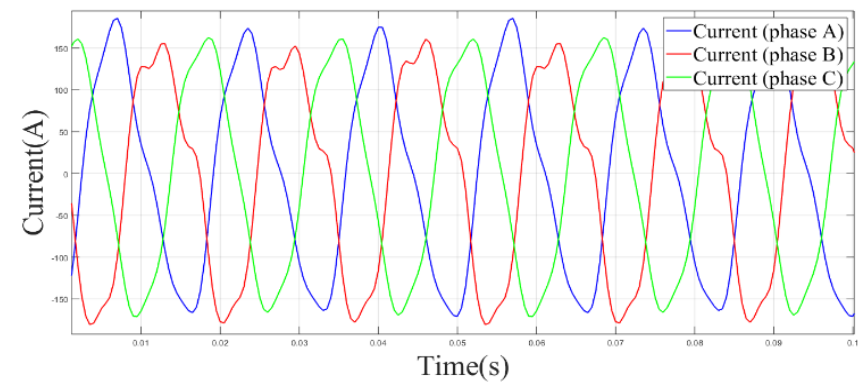

Figure 14. Electric current after compensation of harmonic currents

Figure 14 shows the harmonic currents resulting from the compensation in the electrical system, when applying the ANN controlled based to the hybrid filter. Accordingly, the distortions in the electric currents were reduced by the responses generated by the ANN. Therefore, some reductions in harmonic current are detailed as follows: in phase A, at a frequency of $40 \mathrm{~Hz}$, the harmonic current was 2 amps at a phase angle of 35.2 degrees with a distortion of $1.22 \%$. Also, at $80 \mathrm{~Hz}$, the current was 3.5 amps at a phase angle of 9.96 degrees with a distortion of $2.14 \%$. Additionally, at $180 \mathrm{~Hz}$, the current was 7.4 amps at an angle of -64.7 degrees with a distortion of $4.5 \%$. Therefore, THDI was $17.25 \%$. A similar behavior is noted in phase $\mathrm{B}$.

Among some of the reduction in harmonics in phase $\mathrm{B}$ are: at a frequency of $40 \mathrm{~Hz}$ the harmonic current was 3 amps at a phase angle of 180 degrees with a distortion of $1.83 \%$. Moreover, at a frequency of $300 \mathrm{~Hz}$, the current was 2 amps at a phase angle of 60.7 degrees with a distortion of $1.22 \%$. Besides, at $420 \mathrm{~Hz}$ the current was 1.8 amps at a 17.76 degree angle with $1.1 \%$ distortion. Therefore, THDI was $21.08 \%$. It is also important to mention that a decrease was observed in distortions in phase $\mathrm{C}$.

In phase $\mathrm{C}$, at a frequency of $40 \mathrm{~Hz}$, the electric current was 2.7 amps at a phase angle of -103 degrees with a distortion of $1.7 \%$. Also, at a frequency of $100 \mathrm{~Hz}$, the current was $3 \mathrm{amps}$ at 113 degree phase angle with $1.8 \%$ distortion. Moreover, at a frequency of $180 \mathrm{~Hz}$ the current was $3 \mathrm{amps}$ at a phase angle of 17.4 degrees with a distortion of $1.8 \%$. Therefore, THDI was $7.82 \%$ 
All the results obtained from the ANN allowed to reduce the harmonic distortions that were generated by the cycloconverter. Accordingly, the percentage of individual distortion and total distortion decreased. However, to improve the behavior of the electrical signal, the even harmonics must be reduced.

\subsection{Reduction of harmonics after implementing the passive filter}

To damp even harmonics, the passive filter was designed according to the reactive power required by the electrical grid to improve the power factor (PF). Thus, each filter injected a reactive power of 3739 VAR. Therefore, the PF improved from 0.86 to 0.94 .

Table 2. Single tuned filter components

\begin{tabular}{ccc}
\hline Components & Filter $\boldsymbol{n = 2}$ & Filter $\boldsymbol{n}=\mathbf{4}$ \\
\hline$X_{C n}$ & $15.43 \Omega$ & $12.34 \Omega$ \\
$X_{L n}$ & $3.86 \Omega$ & $0.77 \Omega$ \\
$C_{n}$ & $172 \mu \mathrm{F}$ & $215 \mu \mathrm{F}$ \\
$L_{n}$ & $10.2 \mathrm{mH}$ & $10.2 \mathrm{mH}$ \\
\hline
\end{tabular}

Table 3. Double tuned filter components

\begin{tabular}{cc}
\hline Components & Filter $\boldsymbol{n = 2 , \boldsymbol { n } = \mathbf { 4 }}$ \\
\hline$L_{1}$ & $1.7 \mathrm{mH}$ \\
$C_{1}$ & $386.8 \mu \mathrm{F}$ \\
$L_{2}$ & $934.5 \mu \mathrm{H}$ \\
$C_{2}$ & $1.25 \mathrm{mF}$ \\
\hline
\end{tabular}

Table 2 shows the components of the single tuned filter, such as: capacitive reactance $\left(X_{c n}\right)$, inductive reactance $\left(X_{L n}\right)$, the capacitance $\left(C_{n}\right)$ and inductance $\left(L_{n}\right)$. These filters were related by the resonant frequencies to create an equivalent filter applying the double tuning technique to damp the second and fourth harmonics. The components of the double tuned filter are observed in Table 3.

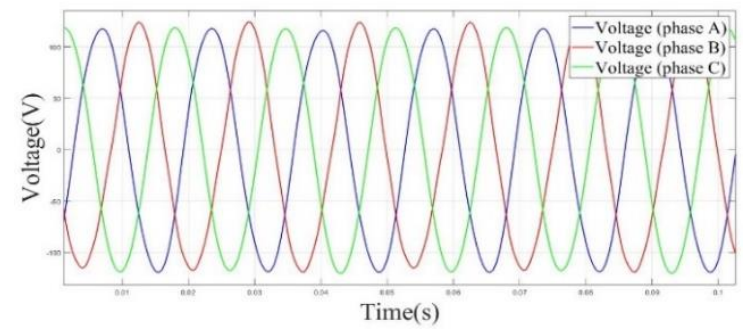

Figure 15. Electrical signal with filtered harmonic voltage

In Figure 15, the voltage after damping the harmonic current due to the operation of the passive filter is shown. Therefore, distortions of even harmonic voltage were reduced. Consequently, the even harmonics after damping the voltage are described as follows: in phase A, at a frequency of $120 \mathrm{~Hz}$, the harmonic voltage was 1.9 volts at a phase angle of -90.5 degrees with a distortion of $1.58 \%$. Likewise, at a frequency of $240 \mathrm{~Hz}$, the voltage was 0.2 volts with a phase angle of 83.25 degrees with a distortion of $0.16 \%$. Therefore, the THDV in the electrical system is $3.5 \%$, which is allowed according to electrical standards. Furthermore, to reduce harmonic distortions in phase $\mathrm{B}$, the double tuned filter was also applied.

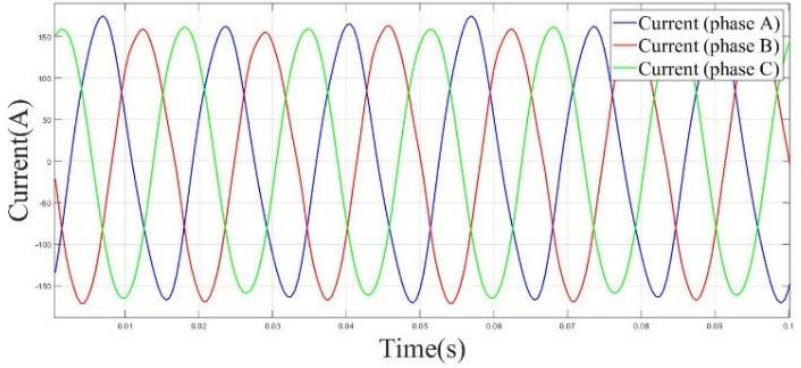

Figure 16. Electrical signal with filtered harmonic current

In phase $\mathrm{B}$, the even harmonics are detailed as follows: at a frequency of $120 \mathrm{~Hz}$, the harmonic voltage was 5 volts at a phase angle -126.6 degrees with a distortion of $4.1 \%$. Furthermore, at a frequency of $240 \mathrm{~Hz}$, the voltage was 0.6 volts at a phase angle of -96.25 degrees with a distortion of $0.5 \%$. Therefore, THDV in phase is $4.7 \%$. Furthermore, as it is observed that the passive filter improved the quality in phase $\mathrm{B}$, it was also applied in phase $\mathrm{C}$.

In phase $\mathrm{C}$, the even harmonics in voltage are described as follows: at $120 \mathrm{~Hz}$ the voltage was 0.5 volts at a phase angle of -81.4 with a distortion of $0.4 \%$. Also, at a frequency of 240 $\mathrm{Hz}$, the electrical voltage was 0.3 volts at a phase angle of 121 degrees with a distortion of $0.25 \%$. Therefore, THDV in phase was $1.65 \%$. As a result of damping the voltage harmonics, harmonic currents in the electrical system decreased as well.

In Figure 16, the current is shown after damping the even harmonics. As a result, current distortions in phase A were reduced, obtaining the following harmonics: at a frequency of $120 \mathrm{~Hz}$, a harmonic current of 6 amperes was presented at a phase angle of -120 degrees with a distortion of $3.6 \%$. Also, at a frequency of $240 \mathrm{~Hz}$, the harmonic current was 0.9 amps at a phase angle of -175 degrees with a distortion of $0.55 \%$. Therefore, THDI in phase was 6.5\%. Moreover, harmonic distortions in current in phase $\mathrm{B}$ were also reduced by damping the even harmonics.

In phase $\mathrm{B}$, the even harmonic currents are detailed as follows: at a frequency of $120 \mathrm{~Hz}$, a current of 8 amperes was obtained at a phase angle of 50 degrees with a distortion of $4.8 \%$. Therefore, at a frequency of $240 \mathrm{~Hz}$, the current was 1.6 amps at a phase angle of 29.5 degrees with a distortion of $0.97 \%$. Consequently, THDI in phase was $5.7 \%$. Similarly, these even harmonic reductions were also produced in phase $\mathrm{C}$ by the operation of the passive filter.

In phase $\mathrm{C}$, the even harmonics are presented as follows: at the frequency of $120 \mathrm{~Hz}$ the current was $1.3 \mathrm{amps}$ at a phase angle of -176 degrees with a distortion of $0.79 \%$. Also, at the frequency of $240 \mathrm{~Hz}$ the current was $1 \mathrm{amp}$ at a phase angle of -120.3 degrees with a distortion of $0.6 \%$. As a result, THDI in phase was $2.7 \%$. Therefore, the designed hybrid filter comprised of a passive filter and an ANN controlled-based filter allowed to reduce the harmonics generated by the threepulse cycloconverter. In addition, the total distortions in the electrical system were reduced in such a way that it complies with IEEE standards.

\section{CONCLUSIONS}

This article presents the reduction of voltage and current harmonics in the electrical system by injecting harmonic current into the electrical grid through of artificial neural networks (ANN). Therefore, it is concluded from the study 
that:

(1) The ANN relates the harmonic voltages, and the harmonic currents generated by the three-pulse cycloconverter, by obtaining expected results in the generalization of the data in the training process. Therefore, the networks established a linear relationship with correlation coefficients greater than 0.90 .

(2) Neural networks generate similar harmonic currents to those produced by the cycloconverter; therefore, in the compensation process, the harmonic distortions of the electrical system were reduced. Consequently, it is shown that neural networks as a hybrid filter control system, compensates for distortions formed by odd harmonic, subharmonic and interharmonic generated by non-linear loads as opposed to previous studies that focused only on a specific group of the forementioned harmonic.

(3) The ability of the neural network to relate not only voltage and current of the odd harmonic; but also, to establish a linear relationship between currents and voltages of the subharmonic and interharmonic in the training process has been proved. Therefore, neural networks as a control system generate harmonic currents at different frequency ranges that includes training.

(4) By incorporating the passive filter for damping even harmonic currents, together with the compensation of harmonic currents by ANN, the reduction of total current and voltage distortions was improved.

(5) The ANN applied as a control system in the hybrid filter, is a method that enables the reduction of the odd harmonics, subharmonics and interharmonics generated by the three-pulse cycloconverters. Therefore, the distortions in the current were reduced to $6.5 \%$ in phase $A, 5.7 \%$ in phase $B$ and $2.7 \%$ in phase $\mathrm{C}$. The results presented, demonstrate that the individual and total distortions of the voltages and currents in each phase in the electrical system were reduced in such a way that the distortions comply with the standards established by the IEEE.

On the other hand, the training of neural networks presents some limitations such as: the numbers of neurons in the hidden layer of a network composed of odd harmonic, subharmonic, and interharmonic were increased by the amount of input data. This causes an overfitting in the network by selecting an inadequate number of neurons, generating deficient results when new input data is presented. In addition, the calculation of local errors in an ANN is increased, which makes it difficult for the algorithm to obtain a minimum error performance that allows establishing a relationship between currents and harmonic voltages.

The next step of the research is to train the ANN with the particle swarm optimization method that allows the neural networks to determine a local minimum error and compare the training results with the ANN trained with the LevenbergMarquardt algorithm. Lastly, to perform a current harmonic compensation test by neural networks in real time, using digital signal processor.

\section{REFERENCES}

[1] Valenzuela, A., Barrera, C., Inga, E. (2020). Electrical assessment of georeferenced distribution network due to electric vehicles deployment. I+D Tecnológico, 16(1): 61-68. https://doi.org/10.33412/idt.v16.1.2441

[2] Agrawal, S., Kumar, P., Palwalia, D.K. (2016). Artificial neural network based three phase shunt active power filter. 2016 IEEE 7th Power India International Conference (PIICON), pp. 1-6. https://doi.org/10.1109/POWERI.2016.8077153

[3] Anggriawan, D.O., Satriawan, A.L., Sudiharto, I., Wahjono, E., Prasetyono, E., Tjahjono, A. (2019). Levenberg marquardt backpropagation neural network for harmonic detection. 2018 Int. Electron. Symp. Eng. Technol. Appl (IES-ETA), pp. 129-132. https://doi.org/10.1109/ELECSYM.2018.8615531

[4] Chiu, Y.B., Chang, G.W., Chen, Y.Y. et al. (2016). Neural network-based approach for determining optimal reference compensation current of shunt active power filter. 2016 IEEE Power and Energy Society General Meeting (PESGM), pp. 1-5. https://doi.org/10.1109/PESGM.2016.7741945

[5] Djerboub, K., Allaoui, T., Champenois, G., Denai, M., Habib, C. (2020). Particle swarm optimization trained artificial neural network to control shunt active power filter based on multilevel flying capacitor inverter. European Journal of Electrical Engineering, 22(3): 199207. https://doi.org/10.18280/ejee.220301

[6] Rajeshwari, Bagwari, A. (2017). Voltage harmonic reduction using passive filter shunt passive-active filters for non-linear load. 2017 7th International Conference on Communication Systems and Network Technologies (CSNT), pp. 131-136. https://doi.org/10.1109/CSNT.2017.8418524

[7] Somlal, J., Mannam, V.G.R., Vutlapalli, N.R. (2015). Power quality improvement in distribution system using ANN based shunt active power filter. International Journal of Power Electronics and Drive Systems, 5(4): 568-575. https://doi.org/10.11591/ijpeds.v5i4.6368

[8] Serrano, V., Tsakalis, K. (2016). A study on the on-line system identification and PID tuning of a buck converter. 2016 IEEE 13th International Conference on Networking, Sensing, and Control (ICNSC), pp. 1-5. https://doi.org/10.1109/ICNSC.2016.7479008

[9] Price, D., Serrano, V. (2019). Co-simulation as a resource for the control of a buck converter. 2019 7th International Engineering, Sciences and Technology Conference (IESTEC), pp. 550-555. https://doi.org/10.1109/IESTEC46403.2019.00104

[10] Carbone, R., Testa, A., Menniti, D., Morrison, R.E., Delaney, E. et al. (1995). Harmonic and interharmonic distortion in current source type inverter drives. 10(3): 1576-1583. https://doi.org/10.1109/61.400942

[11] Li, C., Xu, W., Tayjasanant, T. 2003). Interharmonics: Basic concepts and techniques for their detection and measurement. Electr. Power Syst. Res., 66(1): 39-48. https://doi.org/10.1016/S0378-7796(03)00070-1

[12] IEEE Recommended Practice and Requirements for Harmonic Control in Electric Power Systems, IEEE Std 519-2014 (Revision of IEEE Std 519-1992), pp. 1-29, 11 June

2014. https://doi.org/10.1109/IEEESTD.2014.6826459

[13] Eduardo, F., Díaz, R. (2003). Diseño y construcción de un inversor trifásico multinivel. Tesis de ingeniería. Escuela de Ingeniería, Pontificia Universidad Católica de Chile, Santiago de Chile, Chile. https://hrudnick.sitios.ing.uc.cl/paperspdf/dixon/tesis/Ri os.pdf.

[14] Papriwal, A., Mahor, A. (2012). Mitigation of harmonics in inverter. IOSR Journal of Engineering, 2(9): 98-105. https://doi.org/10.9790/3021-029198105 
[15] He, Y.H., Su., Heng. (2013). A new method of designing double-tuned filter. Proceedings of the 2nd International Conference on Computer Science and Electronics Engineering (ICCSEE 2013), pp. 206-209. https://doi.org/10.2991/iccsee.2013.54

[16] Geno Peter, P. (2010). Design of single phase fully controlled converter using cosine wave crossing control with various protections. International Journal of Engineering Science and Technology, 2(9): 4222-4227.

[17] Álzate, A., Yarce, D.M., Valencia, M., Escalar, A.C. (2011). Control de velocidad mediante relación voltajefrecuencia. 19-24.

[18] Liu, Z.D., Himmel, J., Bonfig, K.W. (2005). Improved processing of harmonics and interharmonics by time- domain averaging. IEEE Transactions on Power Delivery, 20(4): 2370-2380. https://doi.org/10.1109/TPWRD.2005.855477

[19] Blooming, T.M., Carnovale, D.J. (2006). Application of IEEE std 519-1992 harmonic limits. Conference Record of 2006 Annual Pulp and Paper Industry Technical Conference, pp.

1-9. https://doi.org/10.1109/PAPCON.2006.1673767

[20] Wilson, P., Mantooth, H.A. (2013). Model-Based Engineering for Complex Electronic Systems. https://doi.org/10.1016/C2010-0-64918-2

[21] Kůrková, V. (1992). Kolmogorov's theorem and multilayer neural networks. Neural Networks, 5(3): 501506. https://doi.org/10.1016/0893-6080(92)90012-8 